\title{
A Missed Late Presentation of a Congenital Pulmonary Airway Malformation as a Large Infected Bulla
}

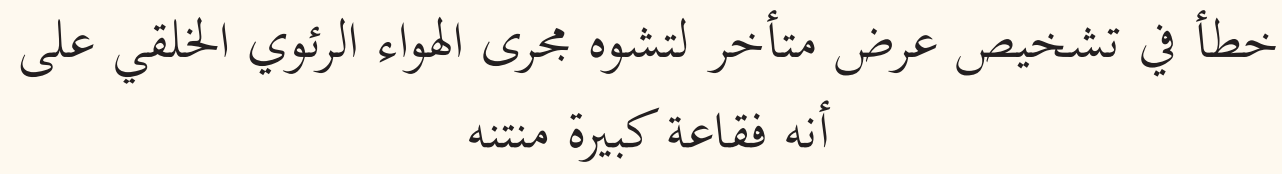

شونج يون لي، سيازارينا شريس عثمان، حلمي محمد نور، نور سفيرا عبد عيسى

ABSTRACT: A congenital pulmonary airway malformation (CPAM) is a rare cystic anomaly that may occur during development of the fetal airways. The vast majority of CPAMs are detected in neonates; as such, it is unusual for diagnosis to occur in adulthood. We report a 21-year-old male patient who presented to the emergency department of the Hospital Ampang, Kuala Lumpur, Malaysia, in 2015 with chest pain, breathlessness and tachypnoea. Based on an initial chest X-ray, the patient was misdiagnosed with pneumothorax and underwent urgent chest tube insertion; however, his condition deteriorated over the course of the next three days. Further imaging was suggestive of infected bullae or an undiagnosed CPAM. The patient therefore underwent video-assisted thoracoscopic surgery, during which a large infected bulla was resected. A diagnosis of an infected CPAM was confirmed by histopathological examination. Following the surgery, the patient recovered quickly and no bullae remnants were found at a one-month follow-up.

Keywords: Respiratory System Abnormalities; Congenital Cystic Adenomatoid Malformation of Lung; Adult; Respiratory Tract Infection; Pneumothorax; Video-Assisted Thoracic Surgery; Case Report; Malaysia.

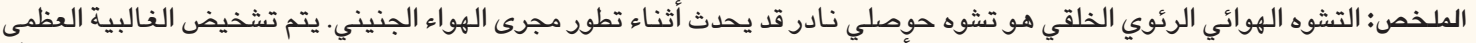

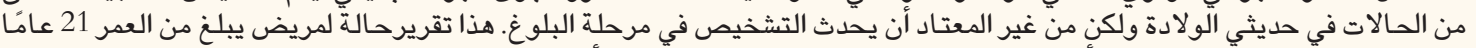

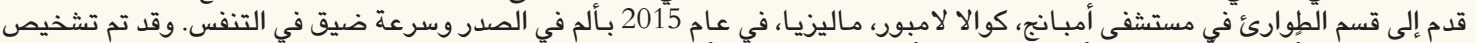

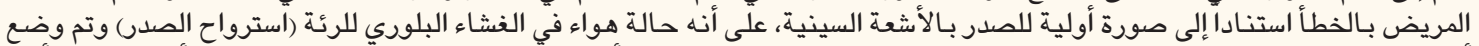

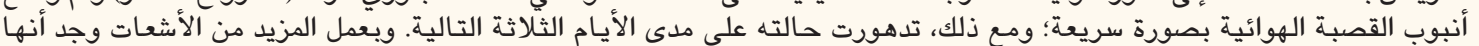

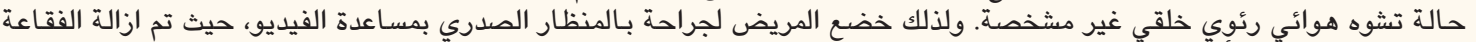

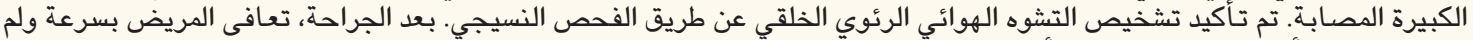

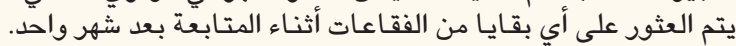

الكلمات المفتاحية: تشوهـات الجهاز التنفسي؛ التشوه الهوائي الرئوي الخلقي؛ الكبار؛ عدوى الجهاز التنفسي؛ استرواح الصدر؛ جراحة الصدر بمساعدة الفيديو؛ تقرير حالة؛ ماليزيا.

A CONGENITAL PULMONARY AIRWAY MALFORMation (CPAM) - formerly known as a congenital cystic adenomatoid malformation-accounts for $25 \%$ of all congenital lung lesions. ${ }^{1,2}$ The vast majority of cases are diagnosed via ultrasonography during the immediate neonatal period. ${ }^{2}$ This report describes a rare case of CPAM first diagnosed in a young adult presenting with dyspnoea secondary to a large infected bulla. The patient was initially misdiagnosed as having pneumothorax based on findings from a chest X-ray.

\section{Case Report}

A 21-year-old male patient with a history of smoking presented to the emergency department of the Hospital Ampang, Kuala Lumpur, Malaysia, in 2015 with chest pain, breathlessness and tachypnoea. On examination, the patient was tachypnoeic with reduced air entry in the left lung on auscultation. There was no recent history of acute illnesses or cough. His leukocyte count was $15,000 / \mathrm{mm}^{3}$

A chest X-ray revealed a large lucency in the left hemithorax with depression of the left hemidiaphragm and a mediastinal shift to the right [Figure 1]. This finding was initially misinterpreted as indicative of left-sided tension pneumothorax; as such, a chest tube was immediately inserted. However, the patient's condition deteriorated over the following three days and he developed sepsis with coagulopathy. Repeat chest $\mathrm{X}$-rays appeared to show non-resolving pneumothorax.

Computed tomography (CT) of the thorax revealed large air-filled lesions in the left upper hemithorax containing fluids and septations causing a mediastinal 


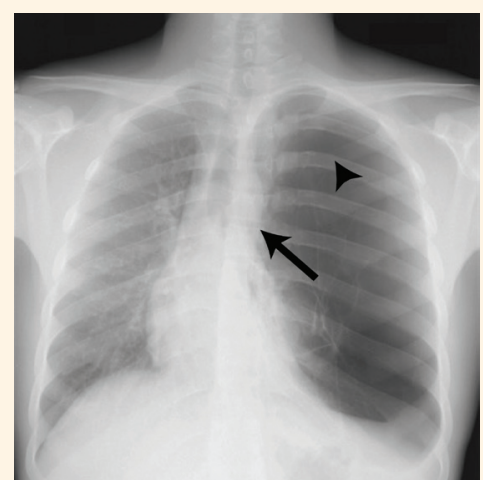

Figure 1: Chest X-ray of a 21-year-old male patient with chest pain, breathlessness and tachypnoea showing lucency (arrow) with reduced lung markings in the left hemithorax and a corresponding increase in lung volume (arrowhead) evidenced by the contralateral mediastinal shift.

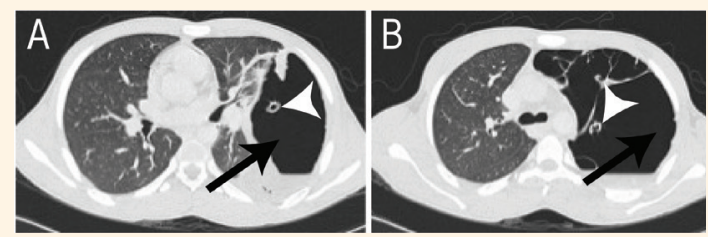

Figure 2: Post-chest tube insertion axial computed tomography scans of the thorax of a 21-year-old male patient showing an air-filled lesion with atelectasis in the left upper lobe (arrow). Note the tip of the chest tube (arrowhead) and the corresponding fluid level.

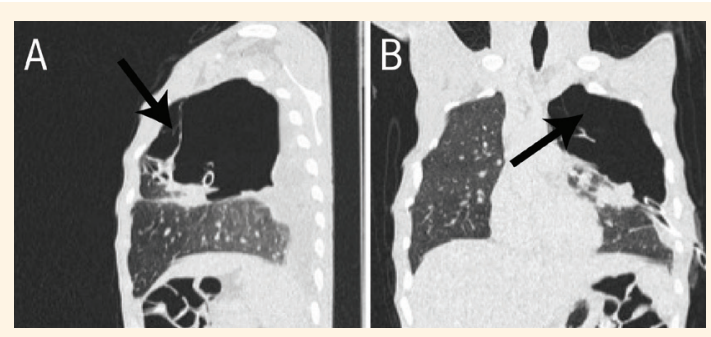

Figure 3: Post-chest tube insertion computed tomography scans of the thorax of a 21-year-old male patient in the (A) sagittal and (B) coronal views showing a septated cystic lesion (arrows) replacing the normal left upper lobe.
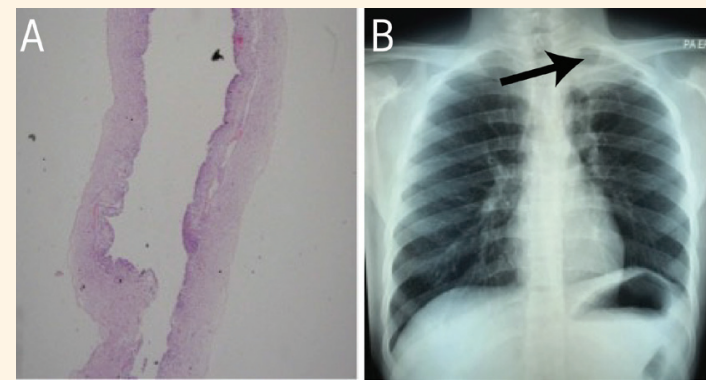

Figure 4: A: Haematoxylin and eosin stain at x100 magnification showing a cystic lesion lined by columnar epithelium. B: Postoperative chest X-ray of a 21-year-old male patient showing thickened left apical pleura (arrow) and the complete resolution of an ipsilateral upper lobe bulla. shift [Figures 2 and 3]. These findings were suggestive of an infected bulla, an undiagnosed CPAM or congenital lobar overinflation (CLO). Accordingly, the patient underwent left video-assisted thoracoscopic surgery (VATS), during which a large infected bulla was identified in the left upper lobe supplied by multiple vessels from the chest wall. The bulla was resected and a histological analysis confirmed a diagnosis of a CPAM with secondary infection [Figure 4A]. After the surgery, the patient quickly recovered following treatment with antibiotics and was discharged. At a one-month follow-up appointment, a chest X-ray showed no bullae remnants [Figure 4B].

\section{Discussion}

A CPAM is a hamartomatous lesion comprising both cystic and adenomatous elements of tracheobronchial and alveolar tissue and is characterised by intracystic communication with and connection to the tracheobronchial tree. ${ }^{2,3}$ The prevalence of CPAM has been estimated to be approximately one in 7,200 pregnancies. $^{2}$ After birth, the lesions may regress, persist or remain stable. ${ }^{3}$ Stocker et al. first described three types of CPAM; however, more recently, these classifications have been expanded to five types reflecting developmental progression through the tracheobronchial tree, from the large airways to the bronchioles and alveoli [Table 1]. 4,5 An alternate classification of CPAM was proposed by Adzick et al., dividing CPAM cases into macrocystic, microcystic or solid lesions based on prenatal ultrasongraphy. ${ }^{6}$

In most cases, CPAM presents in the neonatal period with acute respiratory distress and is characterised by unilateral lower lobe involvement. ${ }^{7}$ Diagnosis in adulthood is rare and can occur either as a result of infection, malignant transformation or discovered incidentally on chest X-ray. ${ }^{8}$ Adult patients with undiagnosed CPAMs can present with recurrent pneumonia, pneumothorax, bullae, haemoptysis or dyspnoea. ${ }^{7,9,10}$ The differential diagnosis in adults includes acquired cystic lesions (i.e. pulmonary tuberculosis [TB]) or congenital lesions (i.e. bronchogenic cysts and pulmonary sequestration). ${ }^{11,12}$ Other renal and cardiac anomalies may also be associated with CPAM. Pulmonary sequestration can be radiologically ruled out as this type of malformation has an anomalous systemic arterial supply, unlike CPAM. ${ }^{13}$ Histological analysis is crucial as this enables identification of the cause of the multicystic mass and excludes pulmonary TB. ${ }^{14}$

In the current case, a retrospective review of the initial chest X-ray indicated a large left-sided bulla causing a contralateral mediastinal shift; however, at the time, the bulla was mistaken for pneumothorax, resulting in the unwarranted insertion of a chest tube. Subseq- 
Table 1: Expanded classification of congenital pulmonary airway malformations ${ }^{5}$

\begin{tabular}{|c|c|c|c|c|c|}
\hline Characteristic & Type 0 & Type 1 & Type 2 & Type 3 & Type 4 \\
\hline Frequency in \% & $1-3$ & $50-65$ & $20-25$ & 8 & 10 \\
\hline Size in $\mathrm{cm}$ & $\leq 0.5$ & $2-10$ & $<2-2.5$ & $0.2-1.5$ & $0.5-7$ \\
\hline Location & Tracheobronchial & $\begin{array}{l}\text { Bronchial/ } \\
\text { bronchiolar }\end{array}$ & Bronchiolar & $\begin{array}{l}\text { Bronchiolar/ } \\
\text { alveolar duct }\end{array}$ & Distal acinar \\
\hline Onset & Birth & Prenatal* & Postnatal & Prenatal $^{*}$ & Postnatal \\
\hline $\begin{array}{l}\text { Clinical } \\
\text { presentation }\end{array}$ & $\begin{array}{c}\text { - Lethal } \\
\text { pulmonary } \\
\text { hypoplasia } \\
\text { - Absence or lack } \\
\text { of alveoli }\end{array}$ & $\begin{array}{c}\text { • None } \\
\text { (asymptomatic) } \\
\text { - Immediate or } \\
\text { delayed respiratory } \\
\text { distress or } \\
\text { infection }\end{array}$ & $\begin{array}{l}\text { - Respiratory } \\
\text { issues }^{\dagger}\end{array}$ & $\begin{array}{c}\text { - Development of } \\
\text { hydrops in prenatal } \\
\text { cases } \\
\text { - Respiratory } \\
\text { distress }{ }^{\ddagger} \text { in } \\
\text { postnatal cases }\end{array}$ & $\begin{array}{c}\text { • None } \\
\text { (asymptomatic) } \\
\text { - Pneumonia or } \\
\text { pneumothorax }\end{array}$ \\
\hline $\begin{array}{l}\text { Risk of } \\
\text { malignancy }\end{array}$ & Unknown & $\begin{array}{l}\text { Risk of bronchiolo- } \\
\text { alveolar carcinoma }\end{array}$ & Unknown & Unknown & $\begin{array}{l}\text { Risk of pleuro- } \\
\text { pulmonary } \\
\text { blastoma }\end{array}$ \\
\hline $\begin{array}{l}\text { Association with } \\
\text { other congenital } \\
\text { anomalies or } \\
\text { conditions }\end{array}$ & $\begin{array}{c}\text { - Cardiovascular } \\
\text { anomalies } \\
\text { - Renal hypoplasia }\end{array}$ & Unknown & $\begin{array}{c}\text { - Renal agenesis or } \\
\text { dysgenesis } \\
\text { - Pulmonary } \\
\text { sequestration } \\
\text { - Congenital } \\
\text { cardiac anomalies }\end{array}$ & Unknown & Unknown \\
\hline
\end{tabular}

${ }^{*}$ Particularly with large cysts. ${ }^{\dagger}$ These are often less significant than associated anomalies. ${ }^{\ddagger}$ Depending on the size of the cyst.

uently, CT scans revealed multicystic air-filled lesions, some of which contained fluid and enhanced the septa; at this point, CLO was suspected due to the unusual involvement of the left upper lobe. However, following VATS, a large infected bulla was identified and histologically confirmed to be a CPAM, likely type 1 as it occupied almost the entire left upper lobe. ${ }^{5}$ Radiology and histology ruled out pulmonary sequestration and pulmonary TB, respectively; however, an association with other renal and cardiac anomalies could not be excluded as this type of screening was not performed in the current case.

Among symptomatic infants with CPAMs, urgent surgical excision is usually advocated because segmental resection may be incomplete, resulting in recurrent infections or persistent pneumothorax. ${ }^{15-18}$ Among 19 surgically-treated infants and children, Pinter et al. reported respiratory infections and chest deformities occurring in seven and eight patients, respectively, over an average follow-up period of 7.7 years. ${ }^{18}$ However, in the current case, the patient underwent VATS dissection of the left upper lobe bulla. In such cases, the risk of recurrent infection-related complications is unknown as there is minimal published research regarding the long-term outcomes of adult patients with resected CPAM lesions. Nevertheless, most CPAM patients remain asymptomatic and otherwise healthy. ${ }^{16}$ Previous research has shown post-lobectomy lung volumes in asymptomatic CPAM patients to be $90 \%$ that of predicted normal values. ${ }^{19}$

\section{Conclusion}

The initial identification and presentation of a CPAM in adulthood is rare; as such, the diagnosis and treatment of such cases is challenging for unsuspecting clinicians and radiologists. Nevertheless, as many cases remain asymptomatic, the prevalence of adult CPAM may be under-reported. Long-term research is needed to assess treatment outcomes in adult CPAM patients.

\section{References}

1. Ch'in KY, Tang MY. Congenital adenomatoid malformation of one lobe of a lung with general anasarca. Arch Pathol (Chic) 1949; 48:221-9.

2. Lau CT, Kan A, Shek N, Tam P, Wong KK. Is congenital pulmonary airwa y malformation really a rare disease? Result of a prospective registry with universal antenatal screening program. Pediatr Surg Int 2017; 33:105-8. https://doi.org/10.1007/s003 83-016-3991-1.

3. Langston C. New concepts in the pathology of congenital lung malformations. Semin Pediatr Surg 2003; 12:17-37. https://doi. org/10.1053/spsu.2003.00001.

4. Stocker JT, Madewell JE, Drake RM. Congenital cystic adenomatoid malformation of the lung: Classification and morphologic spectrum. Hum Pathol 1977; 8:155-71. https://doi.org/ 10.1016/S0046-8177(77)80078-6.

5. Stocker JT, Mani H, Husain AN. The respiratory tract. In: Stocker JT, Dehner LP, Husain AN (Eds). Stocker and Dehner's Pediatric Pathology, 3rd ed. Philadelphia, Pennsylvania, USA: Lippincott, Williams \& Wilkins, 2010. Pp. 441-515.

6. Adzick NS, Harrison MR, Glick PL, Golbus MS, Anderson RL, Mahony BS, et al. Fetal cystic adenomatoid malformation: Prenatal diagnosis and natural history. J Pediatr Surg 1985; 20:483-8. https://doi.org/10.1016/S0022-3468(85)80470-X. 
7. Taștekin E, Usta U, Kaynar A, Ozdemır C, Yalçin O, Ozyilmaz F, et al. Congenital pulmonary airway malformation type 2: A case report with review of the literature Turk Patoloji Derg 2014; 32:200-4. https://doi.org/10.5146/tjpath.2013.01208.

8. Smith JA, Koroscil MT, Hayes JA. Congenital pulmonary airway malformation in the asymptomatic adult: A rare presentation. Respir Med Case Rep 2018; 25:280-1. https://doi.org/10.1016/j. rmcr.2018.10.009.

9. Shupe MP, Kwon HP, Morris MJ. Spontaneous pneumothorax in a teenager with prior congenital pulmonary airway malformation. Respir Med Case Rep 2014; 11:18-21. https://doi.org/10.1 016/j.rmcr.2013.03.003

10. McDonough RJ, Niven AS, Havenstrite KA. Congenital pulmonary airway malformation: A case report and review of the literature. Respir Care 2012; 57:302-6. https://doi.org/10.4187/ respcare.00727.

11. Baral D, Adhikari B, Zaccarini D, Dongol RM, Sah B. Congenital pulmonary airway malformation in an adult male: A case report with literature review. Case Rep Pulmonol 2015; $2015: 743452$. https://doi.org/10.1155/2015/743452.

12. Ankers D, Sajjad N, Green P, McPartland JL. Antenatal management of pulmonary hyperplasia (congenital cystic adenomatoid malformation). BMJ Case Rep 2010; 2010:bcr0120102679. https://doi.org/10.1136/bcr.01.2010.2679.

13. Katzenstein AA. Katzenstein and Askin's Surgical Pathology of Non-Neoplastic Lung Disease, 3rd ed. Philadelphia, Pennsylvania, USA: Saunders, 1997. Pp.468-90.
14. Marshall KW, Blane CE, Teitelbaum DH, van Leeuwen K. Congenital cystic adenomatoid malformation: Impact of prenatal diagnosis and changing strategies in the treatment of the asymptomatic patient. AJR Am J Roentgenol 2000; 175:1551-4. https://doi.org/10.2214/ajr.175.6.1751551.

15. Wong KK, Flake AW, Tibboel D, Rottier RJ, Tam PK. Congenital pulmonary airway malformation: Advances and controversies. Lancet Child Adolesc Health 2018; 2:290-7. https://doi.org/10. 1016/S2352-4642(18)30035-X

16. Leblanc C, Baron M, Desselas E, Phan MH, Rybak A, Thouvenin G, et al. Congenital pulmonary airway malformations: State-ofthe-art review for pediatrician's use. Eur J Pediatr 2017; 176:1559-71. https://doi.org/10.1007/s00431-017-3032-7.

17. Wong A, Vieten D, Singh S, Harvey JG, Holland AJ. Longterm outcome of asymptomatic patients with congenital cystic adenomatoid malformation. Pediatr Surg Int 2009; 25:479-85. https://doi.org/10.1007/s00383-009-2371-5.

18. Pinter A, Kalman A, Karsza L, Verebely T, Szemledy F. Longterm outcome of congenital cystic adenomatoid malformation. Pediatr Surg Int 1999; 15:332-5. https://doi.org/10.1007/s003 830050593.

19. Frenckner B, Freyschuss U. Pulmonary function after lobectomy for congenital lobar emphysema and congenital cystic adenomatoid malformation: A follow-up study. Scand J Thorac Cardiovasc Surg 1982; 16:293-8. https://doi.org/10.3109/1401 7438209101066. 